\title{
Analgesic Effect of Moxibustion with Different Temperature on Inflammatory and Neuropathic Pain Mice: A Comparative Study
}

\author{
Wei Zhou, ${ }^{1,2}$ Ruxue Lei, ${ }^{1}$ Chuanyi Zuo, ${ }^{1}$ Yunqing Yue, ${ }^{1}$ Qin Luo, ${ }^{1}$ Chengshun Zhang, \\ Peng Lv, ${ }^{1}$ Yong Tang, ${ }^{1}$ Haiyan Yin, ${ }^{1}$ and Shuguang $\mathrm{Yu}^{1}$ \\ ${ }^{1}$ Acupuncture and Tuina School, Chengdu University of Traditional Chinese Medicine, Chengdu, Sichuan 610075, China \\ ${ }^{2}$ Department of Rehabilitation Medicine, People's Hospital of Deyang City, Deyang, Sichuan 618000, China
}

Correspondence should be addressed to Haiyan Yin; 20062066@cdutcm.edu.cn and Shuguang Yu; ysg@cdutcm.edu.cn

Received 6 February 2017; Revised 1 May 2017; Accepted 21 August 2017; Published 9 October 2017

Academic Editor: Chang G. Son

Copyright (C) 2017 Wei Zhou et al. This is an open access article distributed under the Creative Commons Attribution License, which permits unrestricted use, distribution, and reproduction in any medium, provided the original work is properly cited.

\begin{abstract}
The aim of this study was to determine whether variation of temperature during moxibustion would generate division of analgesic effect. The moxibustion with different temperatures $\left(37^{\circ} \mathrm{C}, 42^{\circ} \mathrm{C}, 47^{\circ} \mathrm{C}\right.$, and $\left.52^{\circ} \mathrm{C}\right)$ was applied to ST36 acupoint for 30 minutes in chronic inflammatory or neuropathic pain mice. The analgesic effect was evaluated by thermal hyperalgesia test in chronic inflammatory pain and by mechanical allodynia in neuropathic pain, respectively. The results indicated that interventions of moxibustion with different temperature caused different analgesic effect on either chronic inflammatory induced by injection of complete Freund's adjuvant (CFA) or neuropathic pain induced by spared nerve injury (SNI). In chronic inflammatory pain, different moxibustion temperature generated different intensity of analgesic effect: the higher the better. In chronic neuropathic pain, stronger analgesic effect was found in moxibustion with temperature $47^{\circ} \mathrm{C}$ or $52^{\circ} \mathrm{C}$ other than $37^{\circ} \mathrm{C}$ and $42^{\circ} \mathrm{C}$. However, there is no significant difference displayed between moxibustion temperatures $47^{\circ} \mathrm{C}$ and $52^{\circ} \mathrm{C}$ or $37^{\circ} \mathrm{C}$ and $42^{\circ} \mathrm{C}$. It implies that the temperature should be taken into account for moxibustion treatment to chronic inflammatory or neuropathic pain.
\end{abstract}

\section{Introduction}

Chronic pain, including chronic inflammatory and neuropathic pain, has becoming a crucial health threat all over the world [1]. Seeking out an effective approach to relieving pain has been a focus in pain management research. Moxibustion, as an important member in acupuncture family procedures [2], has demonstrated that it could be employed to reduce the pain intensity in different types of pain caused by a variety of diseases [3-7]. Moxibustion therapy is manipulated with ignited mugwort (Artemisia vulgaris from traditional Chinese medicine) directly or indirectly at acupoints or some specific parts of body [8]. Generally speaking, one session of moxibustion stimulation lasts about 30 minutes. In the course of moxibustion treatment, the temperature has been widely recognized as a key factor to affect moxibustion curative effect [9-13]. Clinical and experimental studies have also indicated that moxibustion needs proper moxibustion temperature to achieve better therapeutic effect [14-16].
However, which temperature would be better to produce analgesic effect remains unclear. Therefore, we proposed a hypothesis that different temperature moxibustion would give rise to different analgesic effect in different pattern of pain and designed the experiment to address this issue.

\section{Materials and Methods}

2.1. Animals. Male C57BL/6J mice weighing $20 \pm 2 \mathrm{~g}$ were purchased from the Beijing HuaFuKang Bioscience Co., Ltd. All mice were acclimatized to standard laboratory conditions $\left(24 \pm 2^{\circ} \mathrm{C}\right.$ room temperature, $65 \pm 5 \%$ humidity, on $12 / 12 \mathrm{~h}$ light-dark cycles) with drinking water and food available ad libitum. The experimental procedures were conducted in accordance with the National Institutes of Health (NIH) Guide for the Care and Use of Laboratory Animals [17] and approved by the Animal Ethics Committee of Chengdu University of Traditional Chinese Medicine. 


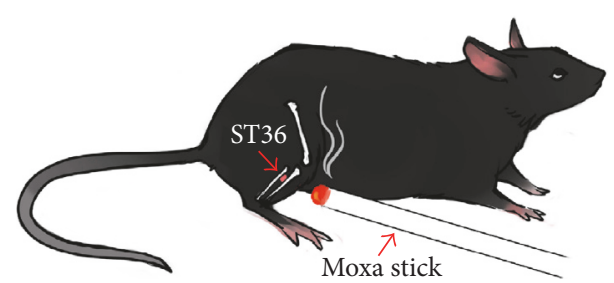

FIGURE 1: Schematic diagram of ST36 location and moxibustion intervention.

After adaptive domestication for one week, mice were firstly randomly divided into two groups: chronic inflammatory pain group and neuropathic pain group, based on random numbers generated by SPSS software. Then, the mice in chronic inflammatory pain group were randomly divided into the following six subgroups: control group, CFA group, CFA-moxi- $37^{\circ} \mathrm{C}$ group, CFA-moxi- $42^{\circ} \mathrm{C}$ group, CFA-moxi$47^{\circ} \mathrm{C}$ group, and CFA-moxi- $52^{\circ} \mathrm{C}$ group $(n=18$ each group). The mice in chronic neuropathic pain group were randomly divided into control (sham surgery) group, SNI group, SNImoxi- $37^{\circ} \mathrm{C}$ group, SNI-moxi- $42^{\circ} \mathrm{C}$ group, SNI-moxi- $47^{\circ} \mathrm{C}$ group, and SNI-moxi-52 $\mathrm{C}$ group ( $n=14$ each group).

2.2. Chronic Inflammatory and Neuropathic Pain Model. Chronic inflammatory pain model was induced by subcutaneously injecting $20 \mu \mathrm{L}$ complete Freund's adjuvant (CFA, Sigma, USA) into the right hind paw [18]. In control group, mice were injected $20 \mu \mathrm{L}$ normal saline (KeLun Industry Group, Sichuan, China) instead of CFA. In this study, thermal hyperalgesia was detected at the fourth day (pain peak time) after CFA injection [19].

Neuropathic pain model was established by spared nerve injury (SNI) [20]. All mice were deeply anaesthetized with isoflurane and were shaved on the right side below the pelvis. The thigh was incised through the skin and then muscle to expose the sciatic nerve and its three terminals branches: the sural, peroneal, and tibial nerves. The peroneal and tibial nerves were isolated from surrounding fascia and were tightly ligated with silk and transected distal to the ligation. Sham operated mice served as controls and underwent the same procedure but did not receive any nerve manipulation. In all surgery groups, the muscle and skin layers were closed separately using absorbable suture, and mice were allowed to recover and got intraperitoneal injection of penicillin (80000 U/kg, North China Pharmaceutical Factory, China) for 3 days to prevent infection. Mechanical hyperalgesia was detected at the fourth day after SNI surgery to assess neuropathic pain model.

2.3. Intervention. Moxibustion was performed at the fourth day after CFA injection and SNI surgery. Moxibustion temperature was set at $37^{\circ} \mathrm{C}, 42^{\circ} \mathrm{C}, 47^{\circ} \mathrm{C}$, and $52^{\circ} \mathrm{C}$ with an interval of $5^{\circ} \mathrm{C}$. Before moxibustion, fur on the outer lateral surface of right hind limb around ST36 (Zusanli acupoint, located at the posterolateral knee of hind limbs, about $2 \mathrm{~mm}$ below the fibular head [21], Figure 1) was shaved to expose ST36. Animal-used moxa sticks (diameter $\times$ length: $8 \mathrm{~mm} \times 20 \mathrm{~cm}$,

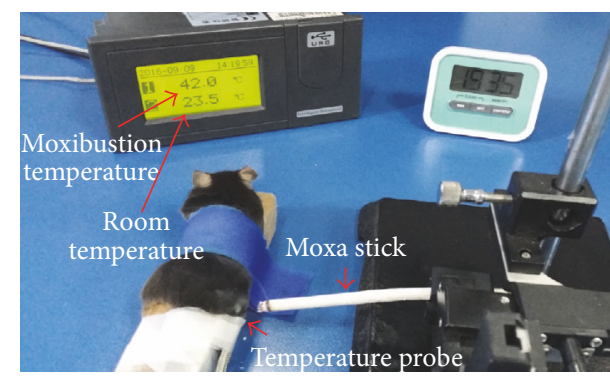

FIgURE 2: Moxibustion intervention.

Nanyang Hanyi Moxibustion Technology Development Co., Ltd., China) were burned to carry out moxibustion over the right ST36 for $30 \mathrm{~min}$ (Figure 1). Mice in control and model group without moxibustion intervention were restricted for 30 min. Moxibustion temperature of ST36 was monitored by a digital thermodetector (WZ-2300R, Xingyi Electronics Company, Hangzhou, China) and stabilized at $37 \pm 1^{\circ} \mathrm{C}, 42 \pm$ $1^{\circ} \mathrm{C}, 47 \pm 1^{\circ} \mathrm{C}$, and $52 \pm 1^{\circ} \mathrm{C}$ (Figures 2 and 3 ).

\subsection{Measurement of Pain Threshold}

2.4.1. Thermal Withdrawal Latency. Thermal hyperalgesia was assessed by measuring the thermal withdrawal latency (TWL) with a Plantar Test Apparatus (Hargreaves method, PL-200, Tai Meng, China). Mice were placed in behavioral boxes on a glass platform [22]. After $30 \mathrm{~min}$ of acclimatization, a mobile radiant heat source (a high-intensity light beam of radiant heat dolorimeter) was focused on the plantar surface of right hind paw. Light intensity was preset at $10 \%$, in order to obtain a baseline latency of $\sim 10 \mathrm{sec}$ and the cutoff time was set at $20 \mathrm{sec}$ to avoid tissue damage. Any of following three responses to thermal stimuli was taken as threshold of pain [23]: (1) the velocity of the withdrawal reflex; (2) the presence or absence of licking; and (3) the duration of the hind paw withdrawal from the floor. The paw TWL was obtained three times per animal with intervals of $5 \mathrm{~min}$. The average from three measurements was calculated as the final result of pain threshold. Paw TWL was tested three times per animal with intervals of $5 \mathrm{~min}$ on day 1 before CFA injection and day 5 before moxibustion, while it was tested only once at the $0 \mathrm{~min}, 30 \mathrm{~min}, 60 \mathrm{~min}, 90 \mathrm{~min}$, and $120 \mathrm{~min}$ after moxibustion intervention separately (Figure 4 ).

2.4.2. Mechanical Withdrawal Threshold. Mechanical hyperalgesia was assessed by detecting mechanical withdrawal threshold (MWT) with a dynamic plantar aesthesiometer (37450, UGO Basile, Germany) [24-27] and expressed in grams. Briefly, the mice were individually placed in the transparent acrylic box under the wire mesh bench, allowing access to the plantar surface of the hind paw. After $20 \mathrm{~min}$ of acclimation, gentle incremental pressure (from 0 to $25 \mathrm{~g}$ over a $10 \mathrm{~s}$ period) was applied using a rigid von Frey hair $(0.5 \mathrm{~mm}$ diameter) to the plantar surface of the ipsilateral hind paw, until the paw was withdrawn. Three tests were conducted at intervals of $5 \mathrm{~min}$ and the force $(\mathrm{g})$ applied was recorded. MWT was averaged from three measurements (before SNI 

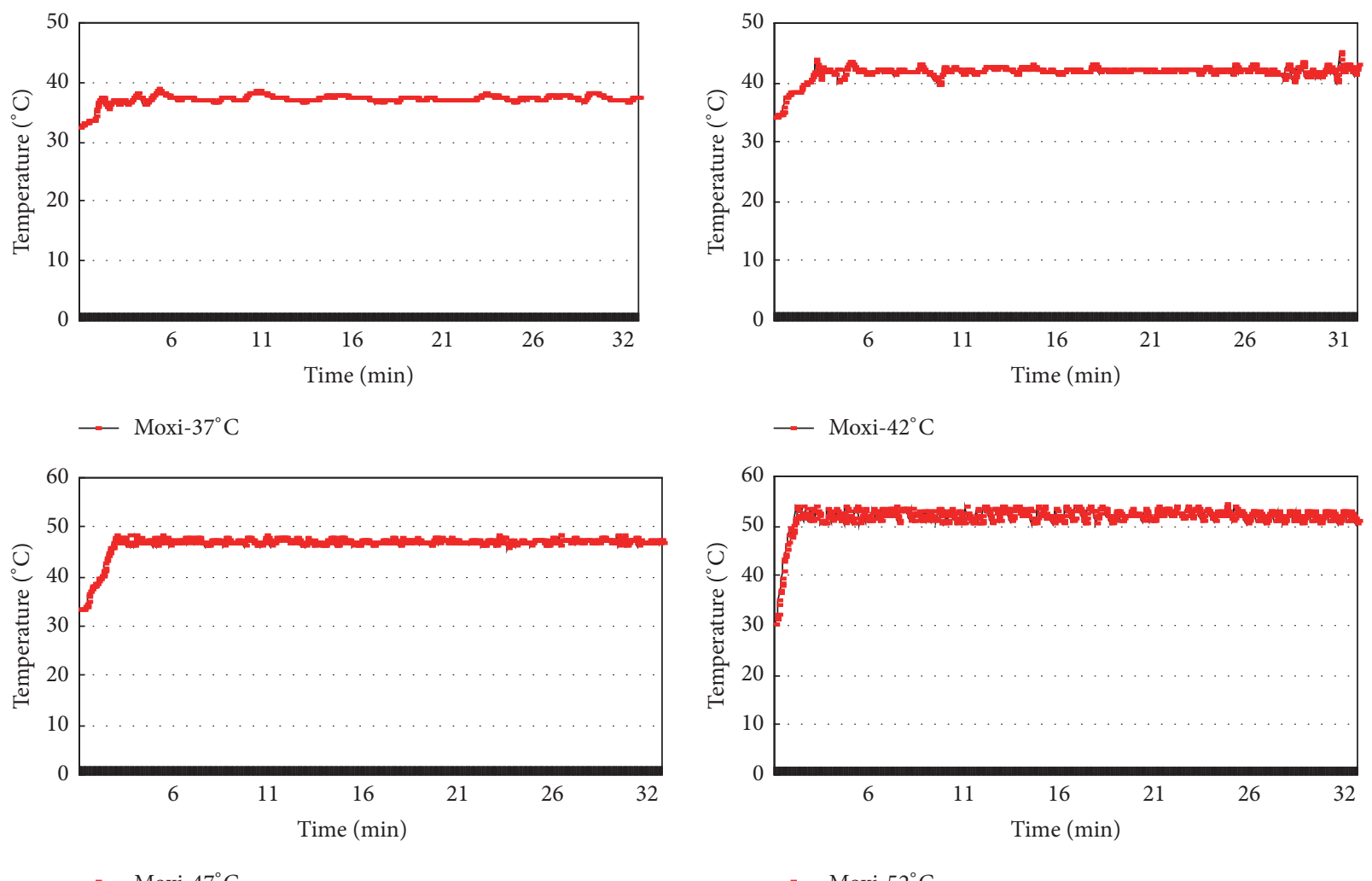

- Moxi- $47^{\circ} \mathrm{C}$

$-\operatorname{Moxi}-52^{\circ} \mathrm{C}$

FIgURE 3: Temperature curves on ST36 during moxibustion.

surgery and after SNI surgery). Each mouse was, respectively, trained for this test on day 1 before SNI surgery, on day 5 before the moxibustion intervention, and at the $0 \mathrm{~min}$, $30 \mathrm{~min}$, $60 \mathrm{~min}$, $90 \mathrm{~min}$, and $120 \mathrm{~min}$ after moxibustion. MWT was measured only once each mouse at five time points after moxibustion intervention. The paw MWL was tested three times per animal with intervals of $5 \mathrm{~min}$ on day 1 before CFA injection and day 5 before moxibustion, while it was tested only once at the $0 \mathrm{~min}, 30 \mathrm{~min}, 60 \mathrm{~min}, 90 \mathrm{~min}$, and 120 min after moxibustion intervention separately (Figure 4).

2.5. Statistical Analysis. All data were analyzed and graphed using Graphpad Prism6 (GraphPad Software, Inc., La Jolla, CA, USA). Data were presented as means \pm SEM (standard error of means). Comparisons among groups were performed by two-way analysis of variance (ANOVA), followed by Tukey's post hoc testing for comparisons between control and experimental groups. A value of $P<0.05$ was considered statistically significant.

\section{Results}

3.1. Thermal Withdrawal Latency. As shown in Figure 5 and Table 1, the TWL-pain threshold in control group nearly did not display any change $(P>0.05)$ at any test point, while after CFA injection, the TWL of CFA group and moxibustion groups was decreased remarkably $(P<0.05)$. Compared with model group, all the four moxibustion groups demonstrated a clear evidence of TWL increasing $(P<0.05)$ at $0 \mathrm{~min}, 30 \mathrm{~min}$,
$60 \mathrm{~min}$, and $90 \mathrm{~min}$ after moxibustion, and all TWL arrived their peaks at $30 \mathrm{~min}$ after moxibustion. Regarding the difference among four different temperatures, TWL of CFA-moxi$52^{\circ} \mathrm{C}$ group was notably higher $(P<0.05)$ than any other moxibustion group, even at $120 \mathrm{~min}$ after moxibustion. And it demonstrated that the higher the moxibustion temperature, the better the analgesic effect (CFA-moxi-37 ${ }^{\circ} \mathrm{C}<$ CFA-moxi$\left.42^{\circ} \mathrm{C}<\mathrm{CFA}-\operatorname{moxi}-47^{\circ} \mathrm{C}<\mathrm{CFA}-\operatorname{moxi}-52^{\circ} \mathrm{C}\right)$.

3.2. Mechanical Withdrawal Threshold. As shown in Figure 6 and Table 2, the MWT of control group nearly did not display any change as time went on $(P>0.05)$, while it was decreased distinctly $(P<0.05)$ in SNI model group. Compared with model group, the MWT of each moxibustion intervention groups was significantly increased $(P<0.05)$ and peaked at $90 \mathrm{~min}$ after moxibustion. Comparing the four different moxibustion groups, a trend at 60 min after moxibustion that the higher moxibustion temperature, the higher MWT could be seen. At $90 \mathrm{~min}$ and $120 \mathrm{~min}$ after moxibustion, the MWT of $47^{\circ} \mathrm{C}$ and $52^{\circ} \mathrm{C}$ moxibustion groups were obviously higher than $37^{\circ} \mathrm{C}$ and $42^{\circ} \mathrm{C}$ moxibustion groups $(P<0.05)$, but there was no statistically significant difference between $52^{\circ} \mathrm{C}$ and $47^{\circ} \mathrm{C}$ group $(P>0.05)$.

\section{Discussion}

Moxibustion temperature was well recognized as a key factor to produce curative effect in moxibustion therapy [6-10]. During moxibustion the temperature at moxibustion site is 


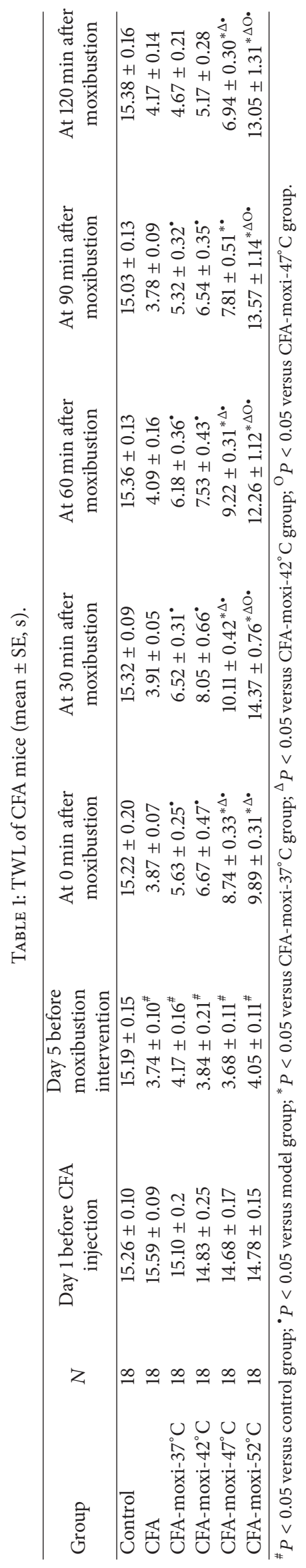




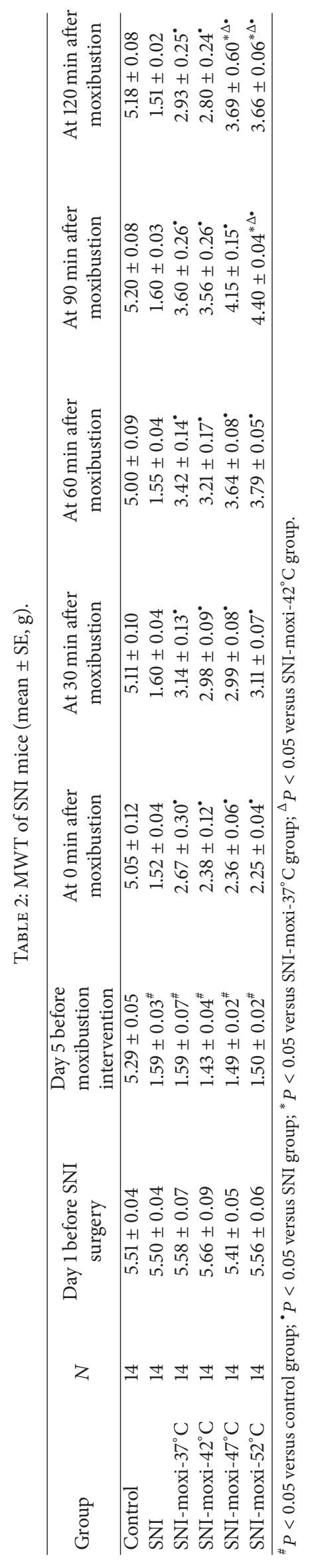




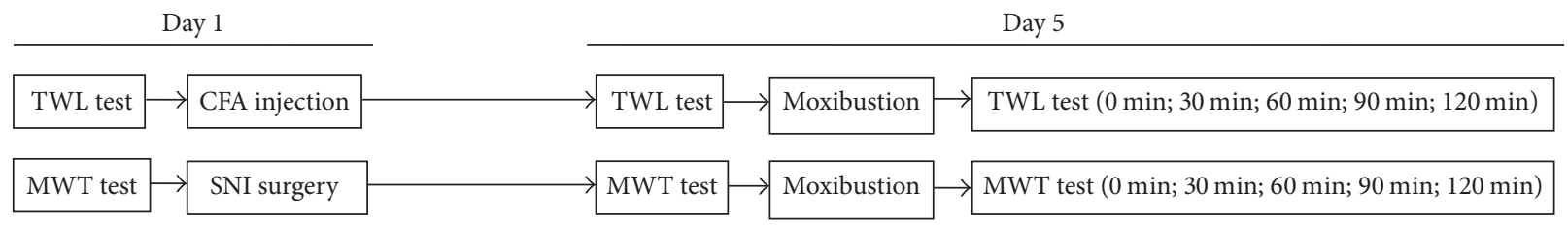

FIgURE 4: Flow chart of the experiment. Notes. TWL and MWT were tested on day 1 before modeling, on day 5 before moxibustion intervention, and at the $0 \mathrm{~min}, 30 \mathrm{~min}, 60 \mathrm{~min}, 90 \mathrm{~min}$, and $120 \mathrm{~min}$ after moxibustion intervention.

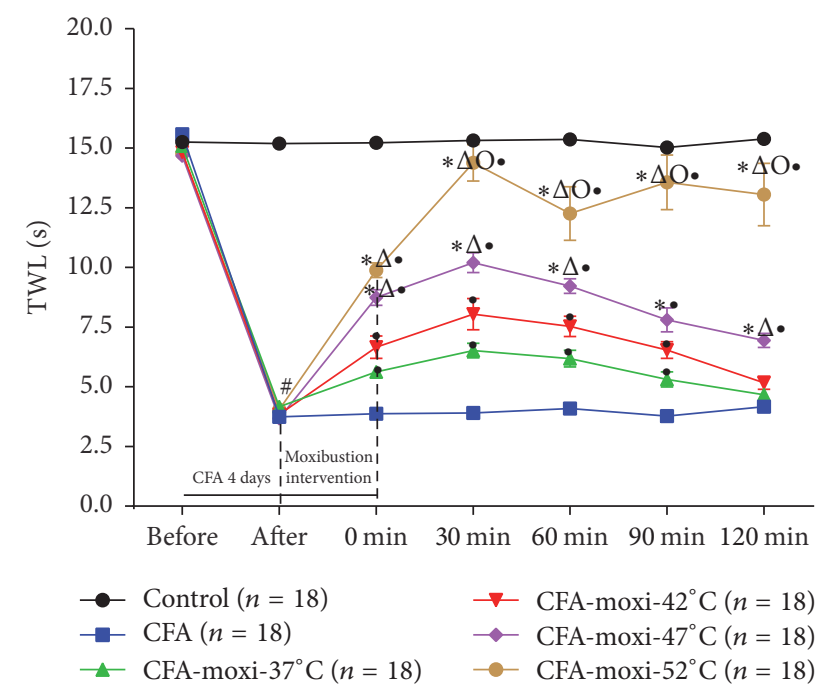

FIGURE 5: Effect of moxibustion on pain threshold of CFA mice. ${ }^{\#} P<0.05$ versus control group; ${ }^{\circ} P<0.05$ versus CFA group; ${ }^{*} P<0.05$ versus CFA-moxi-37 ${ }^{\circ} \mathrm{C}$ group; ${ }^{\Delta} P<0.05$ versus CFAmoxi- $42^{\circ} \mathrm{C}$ group; ${ }^{\mathrm{O}} \mathrm{P}<0.05$ versus $\mathrm{CFA}-\mathrm{moxi}-47^{\circ} \mathrm{C}$ group.

variable within a range from $34^{\circ} \mathrm{C}$ to $57^{\circ} \mathrm{C}[16,28-31]$. However, is there an optimal temperature for moxibustion effect? In irritable bowel syndrome rat model [32], it demonstrated that $46^{\circ} \mathrm{C}, 50^{\circ} \mathrm{C}$, and $54^{\circ} \mathrm{C}$ moxibustion at ST25 acupoint could obviously decrease the visceral hypersensitivity while $38^{\circ} \mathrm{C}$ and $42^{\circ} \mathrm{C}$ moxibustion groups did not show this effect, but there was no obvious difference among $46^{\circ} \mathrm{C}, 50^{\circ} \mathrm{C}$, and $54^{\circ} \mathrm{C}$. In acute hyperlipidemia, $46^{\circ} \mathrm{C}$ moxibustion on CV8 and ST36 acupoints could reduce the level of serum cholesterol, while $38^{\circ} \mathrm{C}$ moxibustion could not [33-36]. Another study indicated that $45^{\circ} \mathrm{C}$ moxibustion temperature could reduce serum IL- $1 \beta$ and TNF- $\alpha$ contents and raising IL- 2 content, while $38^{\circ} \mathrm{C}$ moxibustion has not this effect [37]. The abovementioned studies implied that the relationship between temperature and effect in moxibustion therapy should be a temperate-specific manner.

In this study, we found that moxibustion with 4 different temperature $\left(37^{\circ} \mathrm{C}, 42^{\circ} \mathrm{C}, 47^{\circ} \mathrm{C}\right.$, and $\left.52^{\circ} \mathrm{C}\right)$ obviously generated different analgesic effect in chronic inflammatory and neuropathic pain mice. It suggested that temperature would be really an important impact factor for moxibustion analgesia. We also found that the temperature-related moxibustion analgesic effect patterns were different on different pain model. In chronic inflammatory pain, the data presented that the higher the temperature of moxibustion, the better the

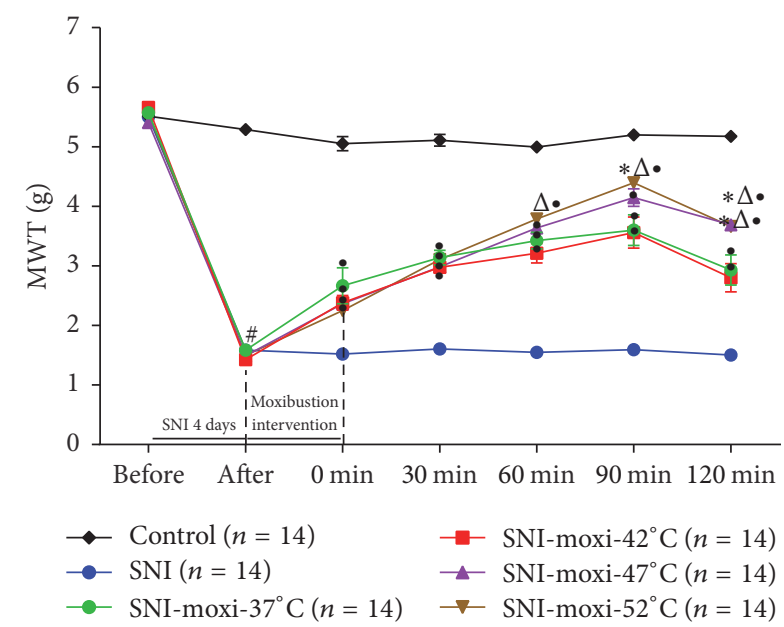

FIgURE 6: Effect of moxibustion on pain threshold of SNI mice. ${ }^{\#} P<0.05$ versus control group; ${ }^{\circ} P<0.05$ versus SNI group; ${ }^{*} P<0.05$ versus SNI-moxi-37 ${ }^{\circ} \mathrm{C}$ group; ${ }^{\Delta} P<0.05$ versus SNImoxi- $42^{\circ} \mathrm{C}$ group.

analgesic effect. In neuropathic pain, the higher temperature $\left(47^{\circ} \mathrm{C}\right.$ or $\left.52^{\circ} \mathrm{C}\right)$ of moxibustion produced stronger analgesic effect that lower temperature $\left(37^{\circ} \mathrm{C}\right.$ or $\left.42^{\circ} \mathrm{C}\right)$, in which similar effect was displayed between $47^{\circ} \mathrm{C}$ and $52^{\circ} \mathrm{C}$ or $37^{\circ} \mathrm{C}$ and $42^{\circ} \mathrm{C}$. Additionally, the peak time of analgesic effect was different between two pain models (inflammatory pain: $30 \mathrm{~min}$ versu neuropathic pain: $90 \mathrm{~min}$ ).

Why the temperature-related moxibustion analgesic effect patterns were different on different pain model? The reason would be that CFA-induced chronic inflammatory pain model is sensitive to thermal stimulus [38, 39], while SNI-induced neuropathic pain model is much sensitive to mechanical stimulus $[32,40,41]$. That was why we employed TWL to access CFA-induced inflammatory pain model while we selected MWL to evaluate SNI-induced neuropathic pain model.

Current data inferred that in moxibustion therapy we should pay attention to not only the temperature but also different pattern of pain in pain management. In future study, clinical trial needs to be performed to confirm this finding from animal study.

\section{Conclusion}

In this study, it is suggested that the higher the temperature of moxibustion, the better the analgesic effect in chronic 
inflammatory mice; in neuropathic pain, the higher temperature $\left(47^{\circ} \mathrm{C}\right.$ or $\left.52^{\circ} \mathrm{C}\right)$ of moxibustion produced stronger analgesic effect that lower temperature $\left(37^{\circ} \mathrm{C}\right.$ or $\left.42^{\circ} \mathrm{C}\right)$, in which similar effect was displayed between $47^{\circ} \mathrm{C}$ and $52^{\circ} \mathrm{C}$ or $37^{\circ} \mathrm{C}$ and $42^{\circ} \mathrm{C}$.

\section{Conflicts of Interest}

The authors declared that there are no conflicts of interest regarding the publication of this paper.

\section{Acknowledgments}

This work was supported by Grants from 973 Program of China (no. 2015CB554504), Sichuan Provincial Innovative Research Team Program (nos. 2014TD0018 and 2015TD0010), Innovative Research Team in University of Sichuan Province (no. 16TD0015), and NSFC of China (no. 81373735).

\section{References}

[1] NIH, Pain Management: Acute and Chronic, 2017.

[2] Y. Tang, H.-Y. Yin, P. Rubini, and P. Illes, "Acupuncture-Induced Analgesia: a Neurobiological Basis in Purinergic Signaling," Neuroscientist, vol. 22, no. 6, pp. 563-578, 2016.

[3] JZ. Yang, Compendium of acupuncture and moxibustion, People's Medical Publishing House, Beijing, China, 1963.

[4] C. P. Yao, The yellow emperor's classic of internal medicine, Zhong Hua Book Company, Beijing, China, 2010.

[5] X. X. Xie and Q. H. Lei, "Observation on therapeutic effect of the spreading moxibustion on rheumatoid arthritis," Chinese Acupuncture and Moxibustion, vol. 28, no. 10, pp. 730-732, 2008.

[6] Z. J. Chen, Y. P. Guo, and Z. C. Wu, "Advances of clinical study on acupuncture and moxibustion for treatment of cancer pain," Chinese Acupuncture and Moxibustion, vol. 28, no. 5, pp. 392394, 2008.

[7] E. Zhou, H. Liu, H. Wu et al., "Herb-partition moxibustion relieves chronic visceral hyperalgesia and 5-HT concentration in colon mucosa of rats," Neurological Research, vol. 31, no. 7, pp. 734-737, 2009.

[8] S. Liu, Q. Shi, Q. Zhu et al., "P2X7 receptor of rat dorsal root ganglia is involved in the effect of moxibustion on visceral hyperalgesia," Purinergic Signalling, vol. 11, no. 2, pp. 161-169, 2015.

[9] S.-H. Yi, "Thermal properties of direct and indirect moxibustion," Journal of Acupuncture and Meridian Studies, vol. 2, no. 4, pp. 273-279, 2009.

[10] H. Deng and X. Shen, "The mechanism of moxibustion: ancient theory and modern research," Evidence-Based Complementary and Alternative Medicine, vol. 2013, Article ID 379291, 7 pages, 2013.

[11] J. S. Petrofsky and M. Laymon, "Heat transfer to deep tissue: the effect of body fat and heating modality," Journal of Medical Engineering and Technology, vol. 33, no. 5, pp. 337-348, 2016.

[12] C. Touchberry, T. Le, S. Richmond et al., "Diathermy treatment increases heat shock protein expression in female, but not male skeletal muscle," European Journal of Applied Physiology, vol. 102, no. 3, pp. 319-323, 2008.

[13] S. F. Lu, H. Y. Yin, Y. Tang et al., "Considerations about study on mechanisms of thermal efficacies of moxibustion from activities of transient receptor potential family," Acupuncture Research, vol. 37, no. 2, pp. 151-154, 2012.

[14] L.-Y. Wu, L. Yang, and C. L. Zhou, "Discussion on the influence factors of moxibustion temperature and the relationship between temperature and the effect of moxibustion," Global Traditional Chinese Medicine, vol. 6, no. 4, pp. 309-313, 2013.

[15] R. X. Chen, M. R. Chen, M. F. Kang et al., "Paying attention to the heat thermal sensitivity of moxibustion is the key for raising the curative effect," Acupuncture Research, vol. 35, no. 4, pp. 311314,2010

[16] J. Jiang, X. Wang, X. Wu et al., "Analysis of factors influencing moxibustion efficacy by affecting heat-activated transient receptor potential vanilloid channels," Journal of Traditional Chinese Medicine, vol. 36, no. 2, pp. 255-260, 2016.

[17] "National research council (US) committee for the update of the guide for the care and use of laboratory animals," in Guide for the Care and Use of Laboratory Animals, National Academies Press, Washington DC, USA, 8th edition, 2011.

[18] D. F. Martins, R. N. Brito, J. Stramosk et al., "Peripheral neurobiologic mechanisms of antiallodynic effect of warm water immersion therapy on persistent inflammatory pain," Journal of Neuroscience Research, vol. 93, no. 1, pp. 157-166, 2015.

[19] P. B. Jacobson, S. J. Morgan, D. M. Wilcox et al., "A new spin on an old model: in vivo evaluation of disease progression by magnetic resonance imaging with respect to standard inflammatory parameters and histopathology in the adjuvant arthritic rat," Arthritis and Rheumatism, vol. 42, no. 10, pp. 2060-2073, 1999.

[20] I. Decosterd and C. J. Woolf, "Spared nerve injury: an animal model of persistent peripheral neuropathic pain," Pain, vol. 87, no. 2, pp. 149-158, 2000.

[21] W. Kim, M. J. Kim, D. Go, B.-I. Min, H. S. Na, and S. K. Kim, "Combined effects of bee venom acupuncture and morphine on oxaliplatin-induced neuropathic pain in mice," Toxins, vol. 8, no. 2, article 33, 2016.

[22] E. S. Fernandes, "Environmental cold exposure increases blood flow and affects pain sensitivity in the knee joints of CFAinduced arthritic mice in a TRPA1-dependent manner," Arthritis Research and Therapy, vol. 18, no. 1, pp. 1-12, 2016.

[23] K. Hargreaves, R. Dubner, F. Brown, C. Flores, and J. Joris, "A new and sensitive method for measuring thermal nociception in cutaneous hyperalgesia," Pain, vol. 32, no. 1, pp. 77-88, 1988.

[24] K.-H. Kim, G.-J. Byeon, H.-Y. Kim, S.-H. Baek, S.-W. Shin, and S.-T. Koo, "Mechanical antiallodynic effect of intrathecal nefopam in a rat neuropathic pain model," Journal of Korean Medical Science, vol. 30, no. 8, pp. 1189-1196, 2015.

[25] S. H. Kim, I. S. Moon, and I. S. Park, "Unique hippocampal changes and allodynia in a model of chronic stress," Journal of Korean Medical Science, vol. 28, no. 6, pp. 946-950, 2013.

[26] J.-F. Fang, Y. Liang, J.-Y. Du, and J.-Q. Fang, "Transcutaneous electrical nerve stimulation attenuates CFA-induced hyperalgesia and inhibits spinal ERK1/2-COX-2 pathway activation in rats," BMC Complementary and Alternative Medicine, vol. 13, no. 3, pp. 1-8, 2013.

[27] P. J. Austin, A. Wu, and G. Moalem-Taylor, "Chronic constriction of the sciatic nerve and pain hypersensitivity testing in rats," ournal of Visualized Experiments, no. 61, article e3393, 2012.

[28] J. Y. Zhang, N. Y. Liu, Z. M. Yang et al., "nfluence and significance of different moxibustion and quantity of mugwort on blood histamine content in rabbits," Chinese Acupuncture and Moxibustion, vol. 21, no. 6, pp. 27-29, 1994. 
[29] J. Z. Wei, X. Y. Shen, G. H. Ding et al., "Analysis of the temperature-time curve of indirect moxibustion," Shanghai Journal of Acupuncture and Moxibustion, vol. 26, no. 12, pp. 3435, 2007.

[30] J. Lin, Y. S. Wang, S. C. Wang et al., "Experimental Ivestigation of acupoint local temperature influence in hyperlipemia (hlp) rats treated by different quantities of warming moxibustion," Chinese Archives of Traditional Chinese Medicine, vol. 29, no. 2, pp. 257-259, 2011.

[31] J. J. Xin, Y. S. Su, Z. K. Yang et al., "Effects of electroacupuncture and regional thermal stimulation at 'Zusanli' (ST 36) on pain thresholds of TRPV 1 knock-out mice," Acupuncture Research, vol. 37, no. 6, pp. 431-439, 2012.

[32] Y. H. Cui, M. M. Zhang, L.-Y. Wu et al., "Effect of mild moxibustion with different temperature for visceral sensitive and TRPV1 protein and TRPV2 protein on ST25 of IBS model rats," China Association of Acupuncture and Moxibustion, 2013.

[33] G. Y. Wang, Y. Wang, K. Lu et al., "Effects of different moxibustion temperature on cholesterol and skin around 'Shenque' (CV 8) in mice with hyperlipidemia," Chinese Acupuncture and Moxibustion, vol. 36, no. 1, pp. 59-63, 2016.

[34] G.-Y. Wang, L.-L. Wang, B. Xu, J.-B. Zhang, and J.-F. Jiang, "Effects of moxibustion temperature on blood cholesterol level in a mice model of acute hyperlipidemia: role of TRPV1," Evidence-Based Complementary and Alternative Medicine, vol. 2013, Article ID 871704, 7 pages, 2013.

[35] J. Y. Gao, G. Y. Wang, and L. L. Wang, "Clinical study on effect of moxibustion on regulation of blood lipid through different moxibustion temperature by TRPV1," Lishizhen Medicine and Materia Medica Research, vol. 26, no. 9, pp. 2182-2184, 2015.

[36] X. Ye and H. Zhang, "Influence of moxibustion temperatures on blood lipids, endothelin-1, and nitric oxide in hyperlipidemia patients," Journal of Traditional Chinese Medicine, vol. 33, no. 5, pp. 592-596, 2013.

[37] B. Xie, L. Wang, J. I. Hui et al., "Capsaicin applied to acupoints at different moxibustion temperatures to efficacy of adjuvant arthritis," Liaoning Journal of Traditional Chinese Medicine, vol. 42, no. 3, pp. 600-603, 2015.

[38] A. K. Singh and M. Vinayak, "Anti-nociceptive effect of resveratrol during inflammatory hyperalgesia via differential regulation of pro-inflammatory mediators," Phytotherapy Research, vol. 30, no. 7, pp. 1164-1171, 2016.

[39] Y.-L. Jiang, X.-F. He, Y.-F. Shen et al., "Analgesic roles of peripheral intrinsic met-enkephalin and dynorphin a in long-lasting inflammatory pain induced by complete freund's adjuvant in rats," Experimental and Therapeutic Medicine, vol. 9, no. 6, pp. 2344-2348, 2015.

[40] X. G. Jin, A. L. Luo, and G. X. Zhang, "Comparison of the establishment and efficacy of three neuropathic pain models," Journal of Clinical Anaesthesiology, vol. 21, no. 5, pp. 338-340, 2005.

[41] M. Richner, O. J. Bjerrum, A. Nykjaer, and C. B. Vaegter, "The spared nerve injury (SNI) model of induced mechanical allodynia in mice," Journal of Visualized Experiments, vol. 18, no. 54, pp. 57-66, 2011. 


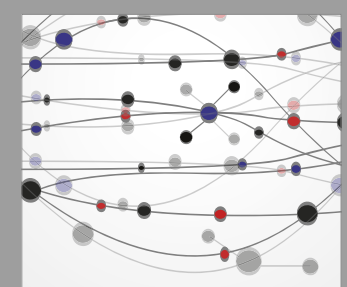

The Scientific World Journal
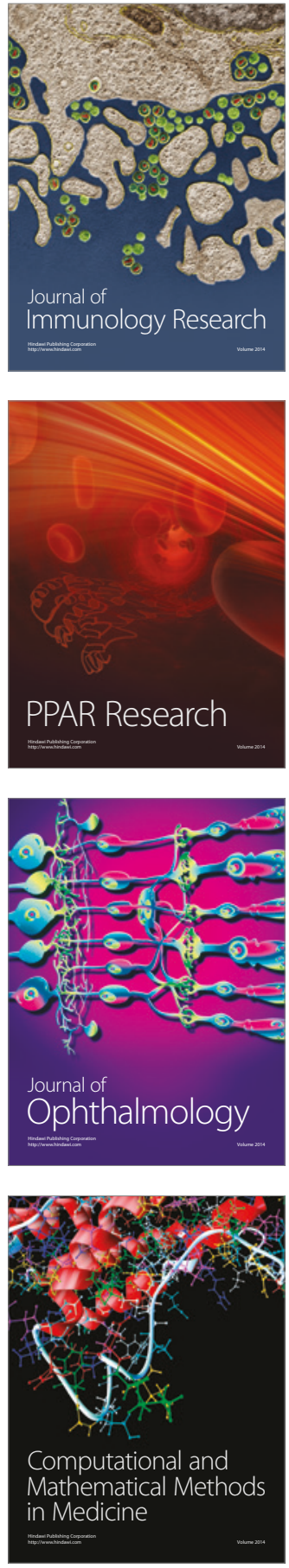

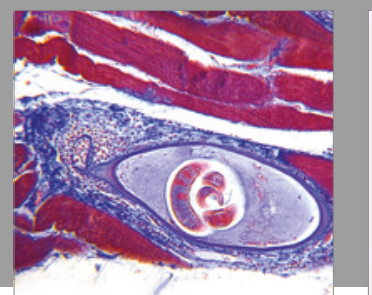

Gastroenterology Research and Practice
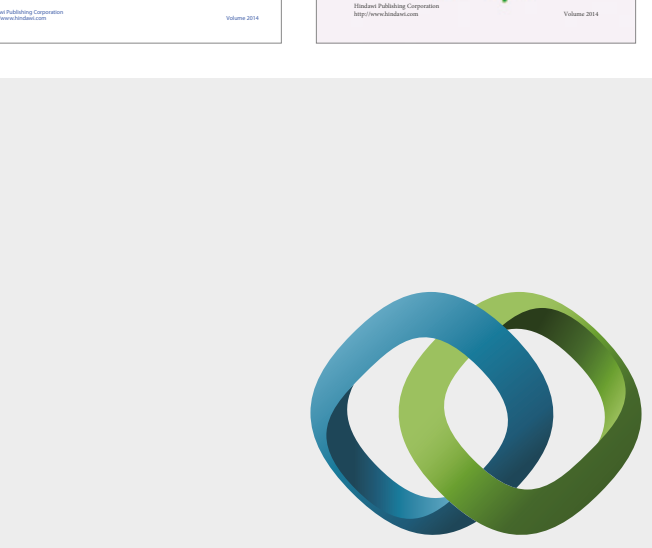

\section{Hindawi}

Submit your manuscripts at

https://www.hindawi.com
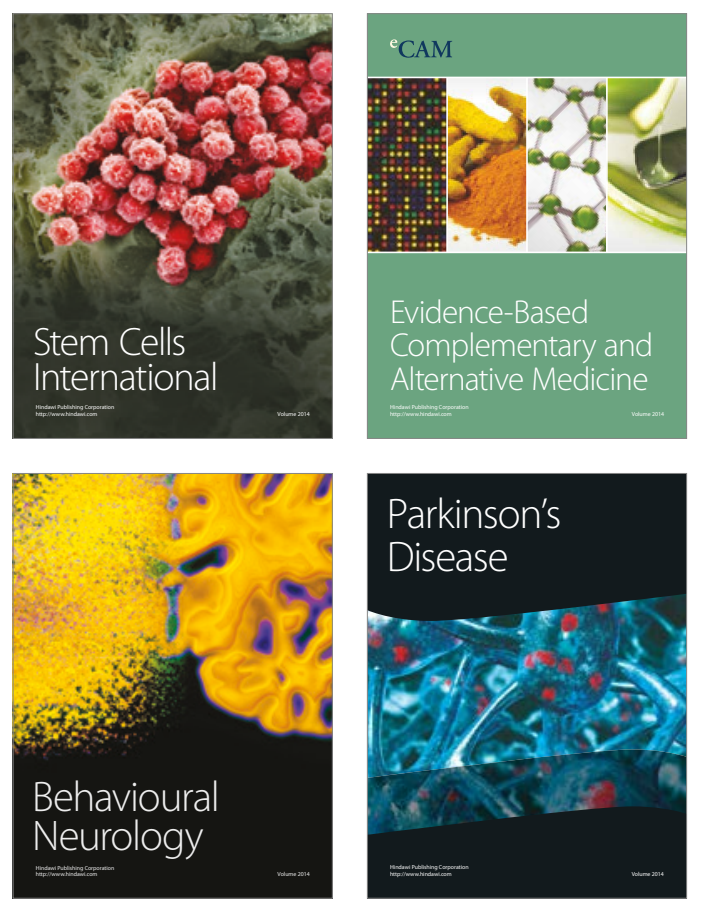
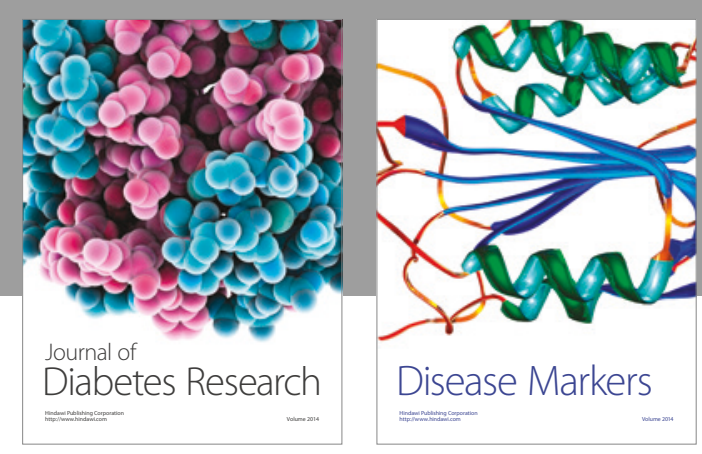

Disease Markers
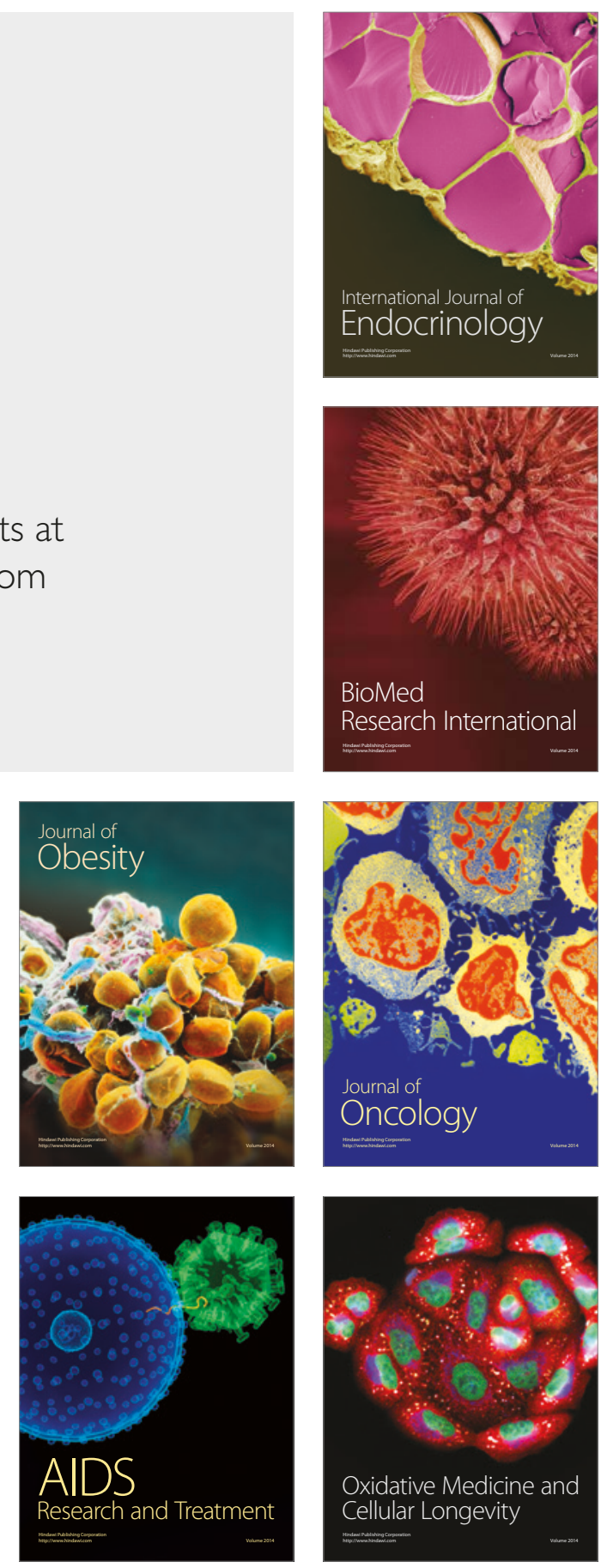